\title{
Psychometric Validation and Reference Norms for the European Spanish Developmental Coordination Disorder Questionnaire: DCDQ-ES
}

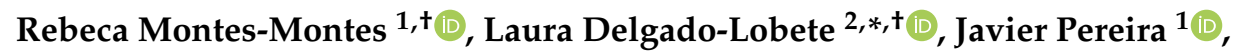 \\ Sergio Santos-del-Riego ${ }^{2}$ (i) and Thais Pousada ${ }^{1}$ (i) \\ 1 TALIONIS Research Group, Research Centre of the Galician University System. Centre for Information and \\ Communications Technology Research (CITIC), Universidade da Coruña, 15008 A Coruña, Spain; \\ rebeca.montes@udc.es (R.M.-M.); javier.pereira@udc.es (J.P.); thais.pousada.garcia@udc.es (T.P.) \\ 2 Health Integration and Promotion Research Unit (INTEGRA SAÚDE), Faculty of Health Sciences, University \\ of A Coruña, 15011 A Coruña, Spain; sergio.santos.delriego@udc.es \\ * Correspondence: 1.delgado@udc.es; Tel.: +34-881-014-339 \\ + Both authors contributed equally to the study.
}

Received: 10 March 2020; Accepted: 1 April 2020; Published: 2 April 2020

check for updates

\begin{abstract}
The Developmental Coordination Disorder Questionnaire (DCDQ) is a widely used and well-validated tool that contributes to the diagnosis of Developmental Coordination Disorder (DCD). The aim of this study was to further analyze the psychometric properties of the European Spanish cross-culturally adapted version of the Developmental Coordination Disorder Questionnaire (DCDQ-ES) in a sample of Spanish children aged 6-11 years and to establish reference norms with respect to age groups. Parents of 540 typically developing children completed the DCDQ-ES. A second sample of 30 children with probable DCD ( $\mathrm{pDCD}$ ) was used to test its discriminant validity. Confirmatory factor analysis supported the original three-factor structure and the internal consistency was excellent (Cronbach's $\alpha=0.907)$. Significant differences between age groups were found. The pDCD group scored significantly lower than the reference sample in the three subscales and DCDQ-ES total score $(p<0.001$; AUC $=0.872)$. The DCDQ-ES is a reliable and valid tool for screening motor coordination difficulties in Spanish children and for identifying children with probable DCD. The findings of this research suggest that context-specific cut-off scores should be systematically utilized when using cross-cultural adaptations of the DCDQ. Age-specific cut-off scores for Spanish children are provided.
\end{abstract}

Keywords: developmental coordination disorder; validity; reliability; screening; parental questionnaire; developmental coordination disorder questionnaire

\section{Introduction}

It is estimated that Developmental Coordination Disorder (DCD) affects approximately $5 \%-10 \%$ of school-aged children, making it the most prevalent neurodevelopmental disorder in childhood [1-3]. Children with DCD present motor coordination difficulties that significantly and persistently limit their daily functioning. As established by the fifth edition of the Diagnostic and Statistical Manual of Mental Disorders (DSM-5), children with DCD must show significantly poorer motor coordination performance than expected from the child's chronological age and opportunity for skill learning and use (criterion A) that significantly and persistently interferes with typical activities of daily living (criterion B), where onset occurs in the early developmental period (criterion C) and that cannot be better explained by a neurological condition affecting movement (criterion D) [2]. 
Children with DCD often struggle with associated developmental problems such as physical problems, sensory processing issues and psychosocial and anxiety difficulties in childhood and adolescence [4-11], and their daily participation in activities is significantly limited in comparison to their typically developing peers [12,13]. In addition, there is a high co-occurrence between DCD and Attention Deficit Hyperactivity Disorder (ADHD) and Autism Spectrum Disorders (ASD) [3,14].

The impact of DCD on daily functioning and participation has been widely reported. Findings from several studies, including a systematic review of 44 articles conducted by Magalhães et al. [12], show that children with DCD have serious activity and participation issues in both productive, leisure and self-care activities, especially in dressing, eating, toileting, sport and outdoor play participation and school-related activities [1,12-17]. In addition, the impact of DCD on everyday performance usually persists during adolescence and adulthood $[8,18]$.

As DCD is a chronic condition with lifelong consequences, it is necessary to identify DCD as early as possible in order to prevent further limitations and promote specific intervention $[3,19,20]$.

While motor coordination test batteries such as Movement Assessment Battery for Children-2 are recommended to assess criterion A, their utilization is usually too time- and resource-consuming for early identification or screening. Therefore, questionnaires aimed at parents have been developed as feasible alternatives to identify children at risk of DCD and to assess criterion B in large groups of children [3]. Screening methods to quickly identify children with motor difficulties in Spain are highly needed, as most of the Spanish children with probable DCD go underdiagnosed in Pediatric Primary Care [21,22].

There are several parent and teacher questionnaires available aimed to operationalize criterion B for DCD diagnosis, such as the Movement Assessment Battery for Children-2 checklist, the Children Activity Scales (both parent and teacher versions) or the DCDDaily-Q [3]. The Developmental Coordination Disorder Questionnaire (DCDQ) [23] is the most used measure to identify children with probable DCD [2,3].

The DCDQ is a three-dimensional, well-validated and easily accessible measure that was developed in Canada and is aimed at assessing motor performance during daily activities in children aged 5-15 years. In order to use it outside Canada, the DCDQ has been successfully cross-culturally adapted to several languages and countries, including Canadian and European French, German, Brazilian, Italian, Polish, Indi and Latin American Spanish [24-31].

The DCDDaily-Q [32] is a newly developed parent questionnaire aimed to comprehensively evaluate motor performance in activities of daily living, including self-care and fine motor and gross motor activities. Although both the DCDQ and the DCDDaily-Q evaluate daily motor performance via parental assessment, the type of activities that are evaluated and the assessments parents are required to make differ between both measures [33].

A European Spanish version of the DCDQ (DCDQ-ES) has been recently translated, cross-culturally adapted and preliminarily validated in Spanish children, but further psychometric validation is needed [34]. Developing custom cut-off points for the Spanish population is also required and recommended, as previous studies have demonstrated that the original proposed cut-off points of the DCDQ may not adjust to South European children [35].

The aims of this study were (1) to test the psychometric properties of the DCDQ-ES and (2) to develop country-adjusted reference norms and cut-off points for Spanish children.

\section{Materials and Methods}

\subsection{Participants, Procedures and Research Ethics}

As children with DCD are usually identified at school-age, two samples of children aged 6 to 11 years were included in the study: a normative group $(n=540,50.0 \%$ boys, mean age $=8.5, \mathrm{SD}=1.7)$ and a probable DCD group $(\mathrm{pDCD})(n=30,66.7 \%$ boys, mean age $=7.9, \mathrm{SD}=1.2)($ Table A1). All 
children in the pDCD group were identified as having probable DCD using the 95th percentile cut-off score on the Spanish version of the DCDDaily-Q (mean score $=46.9, \mathrm{SD}=7.8$ ) [33].

The DCDDaily-Q is a parent questionnaire aimed to operationalize criterion $B$ of the diagnosis of DCD [32]. This measure has demonstrated excellent psychometric properties and capacity to identify children with DCD (Cronbach alpha $=0.85$; sensitivity $=88 \%$; specificity $=92 \%$ ) [32]. All children in the $\mathrm{pDCD}$ group had been referred to two rehabilitation centers in Spain for motor performance issues, and some of them had a previous medical diagnosis of a co-occurring neurodevelopmental condition $(\mathrm{ADHD}=33.3 \%, \mathrm{ASD}=13.3 \%$, no co-occurring disorder $=53.3 \%)$. None of the children in the $\mathrm{pDCD}$ group were receiving specific treatment for DCD.

Participants in the normative group were randomly selected from a previously recruited larger sample that came from fourteen randomly selected mainstream elementary schools located in five locations in northwest, north and center of Spain (northwest $=78.1 \%$, north $=20.2 \%$, center $=$ $1.7 \%)$ [21,33]. Most of the children $(60.6 \%)$ came from a family with high/university education level (i.e., at least one parent held a college degree). Children with a parent-reported diagnosis of a developmental disorder were excluded from this group.

A third group that included children in the normative sample was created to serve as a control group for discriminant validity analysis in order to control for age and sex distribution. Children in the control group were randomly selected from the normative group using age- and sex-stratified sampling to match for exact age and sex with the pDCD group. As the PDCD sample size was small $(n=30)$, a 1:2 ratio was used for the control group $(n=60)$ to increase the statistical power of the analyses [36,37].

This study was approved by the Autonomic Research Ethics of Galicia Committee (code 2017-167). The DCDQ-ES was sent to the parents of the participants between June 2017 and December 2019 via school or rehabilitation center intermediation, so the parents could complete the DCDQ-ES at home.

Parents also received an informative letter about the study, where it was stated that completion of the DCDQ-ES was anonymous and voluntary. The e-mail address and telephone number of the first author were included in the letter so parents could contact the research team for clarification of the items or the questionnaire. Only parents who consented to participate returned the DCDQ-ES to the schools after completion within one week. Researchers retrieved the completed questionnaires from the schools.

\subsection{Measurements}

\section{European-Spanish Version of the DCDQ (DCDQ-ES)}

The DCDQ-ES is a 15-item parent questionnaire designed to screen motor coordination disorders in 5-15-year-old children [23]. Using a five-point Likert scale, parents are asked to evaluate how well their child performs certain motor daily activities compared with their peers $(1=$ not at all like your child; 2 = a bit like your child; $3=$ moderately like your child; $4=$ quite a bit like your child; $5=$ extremely like your child). Items are divided into three subscales or factors: control during movement, fine motor/handwriting and general coordination.

Total and subscale scores are calculated, where higher scores indicate better performance and the total score indicates whether a child has probable DCD with respect to three age groups (5-7 years 11 months; 8-9 years 11 months; and 10-15 years) [24]. The DCDQ usually takes about 10-15 min to complete [23], and it is a well-validated and recommended tool for assessing criterion B of the DSM-5 for a diagnosis of DCD [2,3].

The DCDQ was originally developed in English, and its original validation study using a large sample of Canadian children demonstrated good psychometric properties (Cronbach's alpha = 0.94; sensitivity $=85 \%$; specificity $=71 \%$ ) [23]

Translation into European Spanish, cross-cultural adaptation and preliminary psychometric validation of the DCDQ-ES have been described in a previous study, demonstrating that it is conceptually 
and semantically equivalent to its English version and is a reliable measure for assessing motor coordination in Spanish children [34]. Additionally, the DCDQ-ES has a moderate and significant correlation with the Spanish version of the DCDDaily-Q $(r=0.406$; ICC $=0.381 ; p<0.001)$, which contributes to demonstrating its concurrent validity [33].

The DCDQ-ES is available in the Supplementary Materials (Table S1).

\subsection{Statistical Analysis}

Analyses were performed using SPSS version 24 (SPSS Inc., Chicago, IL, USA) and EQS 6.1 for Windows. To assess the goodness of fit, confirmatory factor analysis (CFA) was conducted using an unweighted least-squares estimation method $(n=540)$ [38-40]. A root-mean-square error of approximation (RMSEA) of $<0.08$, a comparative fit index (CFI) of $>0.95$ and a non-normed fit index (NNFI) of $>0.95$ were indicators that the model fitted the data adequately [41,42].

Reliability of the DCDQ-ES was calculated using Cronbach's alpha, with a value higher than 0.70 considered to be an indication of good internal consistency. Student's $t$-test, analysis of variance (ANOVA) and Bonferroni post-hoc tests were used to determine the discriminant validity of the DCDQ-ES by calculating differences between the control group and the $\mathrm{pDCD}, \mathrm{pDCD}$ only, $\mathrm{pDCD} / \mathrm{ADHD}$ and $\mathrm{pDCD} / \mathrm{ASD}$ groups for mean item scores and mean total and subscale scores. Discriminant validity of the DCDQ-ES across age groups was also tested using Student's $t$-test.

Mean differences according to sex and age group were assessed with Student's $t$-test and ANOVA analysis. Then, the 5 th, 10th, 15th and 20th percentiles of the normative group were calculated for the DCDQ-ES total and subscale scores in the overall sample and within each of the three age groups. ROC computations were conducted and DCDQ-ES total score sensitivity, specificity and predictive values were calculated.

Finally, we explored the potential research consequences of adjusting DCDQ-ES scores for the Spanish population by examining the percentage of children identified as having probable DCD using the original Canadian cut-offs ( $\leq 46$ for ages $6-7 ; \leq 55$ for ages $8-9$; or $\leq 57$ for ages $10-11$ ) or the Spanish-adjusted 5 th percentile cut-offs for each age group.

\section{Results}

\subsection{Construct Validity and Internal Consistency}

The original proposed three-factor model reported an overall good fit to the data (factor $1=$ control during movement (items 1-6); factor $2=$ fine motor/handwriting (items 7-10); factor $3=$ general coordination (items 11-15) $\left(\mathrm{X}^{2}(87)=667.7, p<0.01 ; \mathrm{CFI}=0.974 ; \mathrm{NNFI}=0.969 ; \mathrm{RMSEA}=0.047,95 \%\right.$ $\mathrm{CI}=0.038-0.056$ ). All the loadings were significant and ranged from 0.52 to 0.78 (Figure 1). 


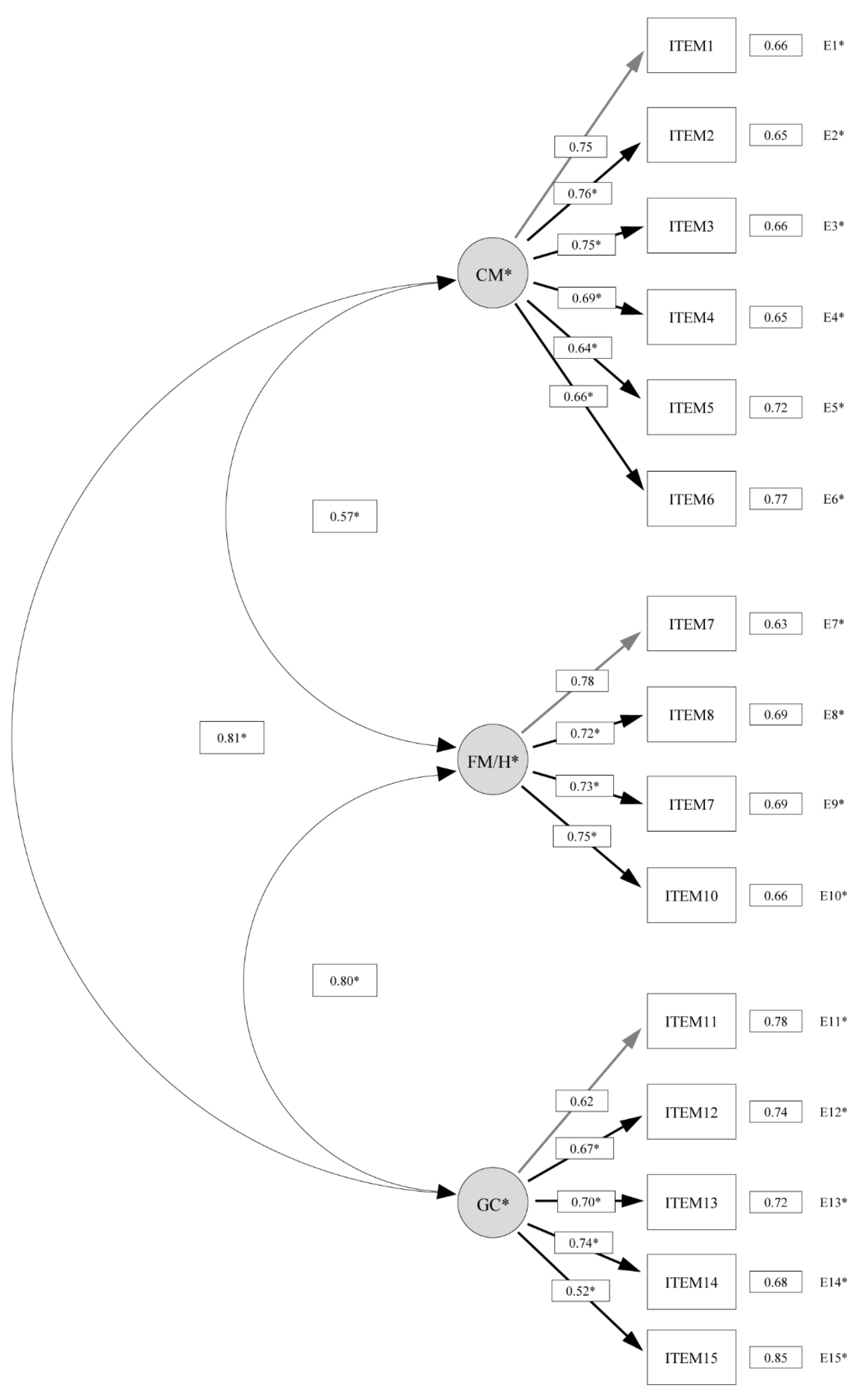

Figure 1. Confirmatory factor analysis of the Spanish version of the Developmental Coordination Disorder Questionnaire (DCDQ-ES) three-factor model $(n=540)$. Items 1,7 and 11 fixed to 1 during estimation. $\mathrm{CM}=$ control during movement; $\mathrm{FM} / \mathrm{H}=$ fine motor/handwriting; $\mathrm{GC}=$ general coordination. 
Internal consistency was excellent for the DCDQ-ES total, and good for the three motor coordination factors (DCDQ-ES total, $\alpha=0.907$; control during movement, $\alpha=0.863$; fine motor/handwriting, $\alpha=0.835$; general coordination, $\alpha=0.775)$. The Cronbach's alpha did not increase if any of the items were deleted, therefore indicating that no item was problematic.

\subsection{Discriminant Validity}

As displayed in Table 1, the total score of the DCDQ-ES showed a good discriminant capacity between typically developing children and children with probable DCD across age groups.

Table 1. DCDQ-ES total and subscale scores for $\mathrm{pDCD}$ and matched control group across age groups $(n=90)$.

\begin{tabular}{cccc}
\hline DCDQ-ES & $\begin{array}{c}\text { pDCD } \\
\text { Mean (SD) }\end{array}$ & $\begin{array}{c}\text { Control } \\
\text { Mean (SD) }\end{array}$ & $p$ Value \\
\hline Total $(n=90)$ & & & \\
Control during movement & $20.4(6.2)$ & $26.8(3.3)$ & $<0.001$ \\
Fine motor/ handwriting & $12.0(5.2)$ & $17.2(3.0)$ & $<0.001$ \\
General coordination & $15.7(5.5)$ & $21.4(3.4)$ & $<0.001$ \\
DCDQ-ES total & $48.1(14.0)$ & $65.5(8.3)$ & $<0.001$ \\
6-7 years $(n=33)$ & & & \\
Control during movement & $18.2(7.3)$ & $26.1(3.1)$ & 0.005 \\
Fine motor/ handwriting & $10.5(5.8)$ & $16.3(2.6)$ & 0.008 \\
General coordination & $14.2(5.7)$ & $21.1(3.2)$ & 0.002 \\
DCDQ-ES total & $42.8(15.3)$ & $63.5(7.7)$ & $<0.001$ \\
8-9 years $(n=48)$ & & & \\
Control during movement & $21.4(5.0)$ & $27.2(3.6)$ & $<0.001$ \\
Fine motor/ handwriting & $13.2(4.7)$ & $17.8(3.2)$ & 0.002 \\
General coordination & $16.9(5.3)$ & $21.5(3.7)$ & $<0.001$ \\
DCDQ-ES total & $51.4(12.9)$ & $66.4(8.8)$ & $<0.001$ \\
10-11 years $(n=9)$. & & & \\
Control during movement & $23.0(7.8)$ & $27.7(2.3)$ & 0.410 \\
Fine motor/ handwriting & $11.7(5.5)$ & $17.7(2.7)$ & 0.056 \\
General coordination & $15.0(6.6)$ & $22.0(3.0)$ & 0.055 \\
DCDQ-ES total & $49.7(12.7)$ & $67.3(7.2)$ & 0.029 \\
\hline
\end{tabular}

$\mathrm{SD}=$ standard deviation; $\mathrm{pDCD}$ = probable Developmental Coordination Disorder.

The pDCD group scored significantly lower than the matched control group, both for the DCDQ-ES total and subscale scores and all items. Children with pDCD only (without ADHD or ASD) also showed significantly poorer scores on the DCDQ-ES total scale and all subscales (Table 2).

Table 2. DCDQ-ES total, subscale and item scores for $\mathrm{pDCD}$ and matched control group $(n=90)$.

\begin{tabular}{|c|c|c|c|c|c|c|}
\hline DCDQ-ES & $\begin{array}{c}\text { pDCD } \\
\text { Mean (SD) } \\
(n=30)\end{array}$ & $\begin{array}{l}\text { pDCD only } \\
\text { Mean (SD) } \\
(n=16)\end{array}$ & $\begin{array}{c}\text { pDCD/ } \\
\text { ADHD } \\
\text { Mean (SD) } \\
(n=10)\end{array}$ & $\begin{array}{c}\text { pDCD/ } \\
\text { ASD } \\
\text { Mean (SD) } \\
(n=4)\end{array}$ & $\begin{array}{c}\text { Control } \\
\text { Mean (SD) } \\
(n=60)\end{array}$ & $\begin{array}{l}p \text { Value within } \\
\text { Groups }\end{array}$ \\
\hline Item 1 & $3.0(1.3)$ & $3.4(1.2)$ & $2.9(1.2)$ & $1.8(1.5)$ & $4.4(0.8)$ & $\begin{array}{l}<0.001^{\mathrm{a}} ; 0.002^{\mathrm{b}} ; \\
<0.001^{\mathrm{c}} ;<0.001^{\mathrm{d}}\end{array}$ \\
\hline Item 2 & $2.8(1.3)$ & $3.1(1.1)$ & $2.8(1.4)$ & $1.8(1.5)$ & $4.5(0.7)$ & $\begin{array}{l}<0.001^{a} ;<0.001^{b} ; \\
<0.001^{c} ;<0.001^{d}\end{array}$ \\
\hline Item 3 & $2.7(1.4)$ & $2.9(1.1)$ & $2.7(1.7)$ & $2.0(2.0)$ & $4.1(1.0)$ & $\begin{array}{r}0.004^{\mathrm{a}} ; 0.004^{\mathrm{b}} \\
0.004^{\mathrm{c}} ;<0.0011^{\mathrm{d}}\end{array}$ \\
\hline
\end{tabular}


Table 2. Cont.

\begin{tabular}{|c|c|c|c|c|c|c|}
\hline DCDQ-ES & $\begin{array}{c}\text { pDCD } \\
\text { Mean (SD) } \\
(n=30)\end{array}$ & $\begin{array}{l}\text { pDCD only } \\
\text { Mean (SD) } \\
(n=16)\end{array}$ & $\begin{array}{c}\text { pDCD/ } \\
\text { ADHD } \\
\text { Mean (SD) } \\
(n=10)\end{array}$ & $\begin{array}{c}\text { pDCD/ } \\
\text { ASD } \\
\text { Mean (SD) } \\
(n=4)\end{array}$ & $\begin{array}{c}\text { Control } \\
\text { Mean (SD) } \\
(n=60)\end{array}$ & $\begin{array}{l}p \text { Value within } \\
\text { Groups }\end{array}$ \\
\hline Item 4 & $4.0(1.2)$ & $4.3(0.9)$ & $4.1(1.4)$ & $3.0(1.6)$ & $4.6(0.7)$ & $\begin{array}{l}0.033^{\mathrm{a}} ; 1.000^{\mathrm{b}} ; \\
0.760^{c} ; 0.004^{d}\end{array}$ \\
\hline Item 5 & $4.0(1.2)$ & $4.1(1.0)$ & $4.3(1.3)$ & $2.8(1.5)$ & $4.6(0.6)$ & $\begin{array}{r}0.016^{\mathrm{a}} ; 0.213^{\mathrm{b}} \\
1.000^{\mathrm{c}} ;<0.001 \mathrm{~d}\end{array}$ \\
\hline Item 6 & $3.8(1.2)$ & $4.1(1.0)$ & $3.8(1.4)$ & $3.0(1.4)$ & $4.8(0.5)$ & $\begin{array}{l}<0.001^{a} ; 0.012^{b} ; \\
0.003^{c} ;<0.001{ }^{d}\end{array}$ \\
\hline Item 7 & $3.0(1.5)$ & $3.5(1.4)$ & $2.3(1.1)$ & $3.0(2.3)$ & $4.3(0.8)$ & $\begin{array}{l}<0.001^{a} ; 0.053^{b} \\
<0.001^{c} ; 0.119^{d}\end{array}$ \\
\hline Item 8 & $3.0(1.6)$ & $3.6(1.7)$ & $2.5(1.4)$ & $1.8(1.0)$ & $4.4(0.9)$ & $\begin{array}{l}<0.001^{a} ; 0.082^{b} \\
<0.001^{c} ;<0.001^{d}\end{array}$ \\
\hline Item 9 & $3.0(1.4)$ & $3.6(1.3)$ & $2.3(1.1)$ & $2.5(1.7)$ & $4.2(1.0)$ & $\begin{array}{l}<0.001^{\mathrm{a}} ; 0.357^{\mathrm{b}} \\
<0.001^{\mathrm{c}} ; 0.017^{\mathrm{d}}\end{array}$ \\
\hline Item 10 & $3.0(1.4)$ & $3.4(1.3)$ & $2.6(1.2)$ & $2.0(1.4)$ & $4.3(0.9)$ & $\begin{array}{l}<0.001^{\mathrm{a}} ; 0.029^{\mathrm{b}} ; \\
<0.001^{\mathrm{c}} ;<0.001^{\mathrm{d}}\end{array}$ \\
\hline Item 11 & $3.5(1.5)$ & $3.8(1.5)$ & $3.8(1.1)$ & $1.8(1.0)$ & $4.6(0.7)$ & $\begin{array}{l}0.001^{\mathrm{a}} ; 0.011^{\mathrm{b}} \\
0.087^{\mathrm{c}} ;<0.001^{\mathrm{d}}\end{array}$ \\
\hline Item 12 & $3.4(1.4)$ & $4.0(1.2)$ & $3.2(1.2)$ & $1.5(1.0)$ & $4.4(0.7)$ & $\begin{array}{l}<0.001^{a} ; 0.666^{b} ; \\
0.001^{c} ;<0.001^{d}\end{array}$ \\
\hline Item 13 & $2.7(1.4)$ & $3.3(1.4)$ & $1.8(0.9)$ & $2.3(1.3)$ & $4.3(1.0)$ & $\begin{array}{l}<0.001^{\mathrm{a}} ; 0.014^{\mathrm{b}} \\
<0.001^{c} ; 0.003^{\mathrm{d}}\end{array}$ \\
\hline Item 14 & $3.3(1.5)$ & $3.8(1.4)$ & $3.1(1.4)$ & $1.8(1.0)$ & $4.3(1.0)$ & $\begin{array}{l}0.002^{\mathrm{a}} ; 0.793^{\mathrm{b}} \\
0.014^{\mathrm{c}} ;<0.001^{\mathrm{d}}\end{array}$ \\
\hline Item 15 & $2.8(1.5)$ & $3.5(1.5)$ & $1.8(0.9)$ & $2.8(1.7)$ & $3.9(1.1)$ & $\begin{array}{l}0.001^{\mathrm{a}} ; 1.000^{\mathrm{b}} ; \\
<0.001^{\mathrm{c}} ; 0.388^{\mathrm{d}}\end{array}$ \\
\hline $\begin{array}{c}\text { Control } \\
\text { during } \\
\text { movement }\end{array}$ & $20.4(6.2)$ & $21.8(4.4)$ & $20.6(6.8)$ & $14.3(8.8)$ & 26.8 (3.3) & $\begin{array}{l}<0.001^{\mathrm{a}} ;<<0.001^{\mathrm{b}} ; \\
<0.001^{\mathrm{c}} ;<0.001^{\mathrm{d}}\end{array}$ \\
\hline $\begin{array}{l}\text { Fine motor/ } \\
\text { handwriting }\end{array}$ & $12.0(5.2)$ & $14.2(4.9)$ & $9.7(4.2)$ & $9.3(5.6)$ & $17.2(3.0)$ & $\begin{array}{l}<0.001^{\mathrm{a}} ; 0.025^{\mathrm{b}} ; \\
<0.001^{\mathrm{c}} ;<0.001^{\mathrm{d}}\end{array}$ \\
\hline $\begin{array}{c}\text { General } \\
\text { coordination }\end{array}$ & $15.7(5.5)$ & $18.4(5.0)$ & $13.7(3.8)$ & $10.0(5.5)$ & $21.4(3.4)$ & $\begin{array}{l}<0.001^{\mathrm{a}} ; 0.035^{\mathrm{b}} ; \\
<0.001^{\mathrm{c}} ;<0.001^{\mathrm{d}}\end{array}$ \\
\hline $\begin{array}{l}\text { DCDQ-ES } \\
\text { total }\end{array}$ & $48.1(14.0)$ & $54.3(10.7)$ & $44.0(11.8)$ & 33.5 (18.6) & $65.5(8.3)$ & $\begin{array}{l}<0.001^{a} ;<0.001^{b} ; \\
<0.001^{c} ;<0.001^{d}\end{array}$ \\
\hline
\end{tabular}

$\mathrm{SD}=$ standard deviation; $\mathrm{pDCD}=$ probable Developmental Coordination Disorder $;=\mathrm{ADHD}=$ Attention Deficit

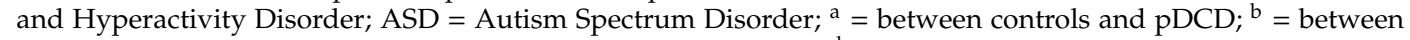
controls and pDCD only; ${ }^{\mathrm{c}}=$ between controls and pDCD/ADHD; ${ }^{\mathrm{d}}=$ between controls and pDCD/ASD.

\subsection{Age and Sex Differences and Age-Specific Cut-Offs}

Significant differences between age groups were found in the DCDQ-ES total scale and all subscales $(p<0.001)$. Younger children scored significantly lower than their older peers in the DCDQ-ES total scale and subscales.

Differences between sex groups were found only in one subscale. In the overall normative sample, girls scored significantly higher than boys in fine motor/handwriting $(p<0.001)$, but not in control during movement $(p=0.424)$, general coordination $(p=0.084)$ or total score $(p=0.228)$.

Therefore, percentiles for all subscales and total score were calculated separately for each age group. In total, four cut-off points for each age group were calculated according to the 5th, 10th, 15th and 20th percentiles on the normative group for DCDQ-ES total and subscales (Table 3). The 15th percentile cut-off point of the DCDQ-ES for the total sample was 57 or below, with a sensitivity of $76.7 \%$ and a specificity of $83.3 \%$ (AUC $=0.872,95 \% \mathrm{CI}=0.798-0.948, n=90)$ (Table 4; Figure 2). 
Table 3. Overall and age-specific cut-off points according to the 5th, 10th, 15th and 20th percentiles for the DCDQ-ES total and subscores in the normative group $(n=540)$.

\begin{tabular}{ccccc}
\hline DCDQ-ES Total and Subscales & p5 & p10 & p15 & p20 \\
\hline Normative group $(n=540)$ & & & & \\
Control during movement & 19 & 21 & 22 & 24 \\
Fine motor/ handwriting & 12 & 14 & 15 & 16 \\
General coordination & 15 & 17 & 18 & 19 \\
DCDQ-ES & $\mathbf{4 9}$ & 55 & $\mathbf{5 7}$ & 59 \\
6-7 years old & & & & \\
Control during movement & 18 & 20 & 21 & 22 \\
Fine motor/ handwriting & 12 & 13 & 14 & 15 \\
$\quad$ General coordination & 14 & 16 & 17 & 18 \\
$\quad$ DCDQ-ES & $\mathbf{4 6}$ & 50 & $\mathbf{5 4}$ & 57 \\
$\quad$ 8-9 years old & & & & \\
Control during movement & 19 & 21 & 22 & 24 \\
Fine motor/ handwriting & 12 & 14 & 15 & 16 \\
$\quad$ General coordination & 15 & 17 & 19 & 19 \\
$\quad$ DCDQ-ES & $\mathbf{5 0}$ & 55 & $\mathbf{5 8}$ & 60 \\
$\quad$ 10-12 years old & & & & \\
Control during movement & 21 & 23 & 24 & 24 \\
Fine motor/ handwriting & 13 & 15 & 16 & 16 \\
$\quad$ General coordination & 16 & 17 & 19 & 20 \\
$\quad$ DCDQ-ES & $\mathbf{5 3}$ & 56 & $\mathbf{5 9}$ & 61
\end{tabular}

In bold = recommended cut-offs for DCD indication (criterion B) in clinical practice (p15) and research (p5).

Table 4. Predictive values and Youden's index of the 5 th and the 15 th percentiles $(n=90)$.

\begin{tabular}{cccccccc}
\hline $\begin{array}{c}\text { DCDQ-ES } \\
\text { Total Score }\end{array}$ & $\begin{array}{c}\text { FP } \\
\text { N (\%) }\end{array}$ & $\begin{array}{c}\text { FN } \\
\text { N (\%) }\end{array}$ & $\begin{array}{c}\text { TP } \\
\text { N (\%) }\end{array}$ & $\begin{array}{c}\text { TN } \\
\text { N (\%) }\end{array}$ & PPV & NPV & $\begin{array}{c}\text { Youden's } \\
\text { Index }\end{array}$ \\
\hline p15 (57) & $10(16.7)$ & $7(23.3)$ & $23(76.7)$ & $50(83.3)$ & $69.7 \%$ & $87.7 \%$ & 0.833 \\
p5 (49) & $1(1.7)$ & $16(53.3)$ & $14(46.7)$ & $59(98.3)$ & $93.3 \%$ & $78.7 \%$ & 0.450 \\
\hline
\end{tabular}

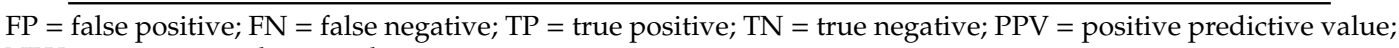
$\mathrm{NPV}=$ negative predictive value.

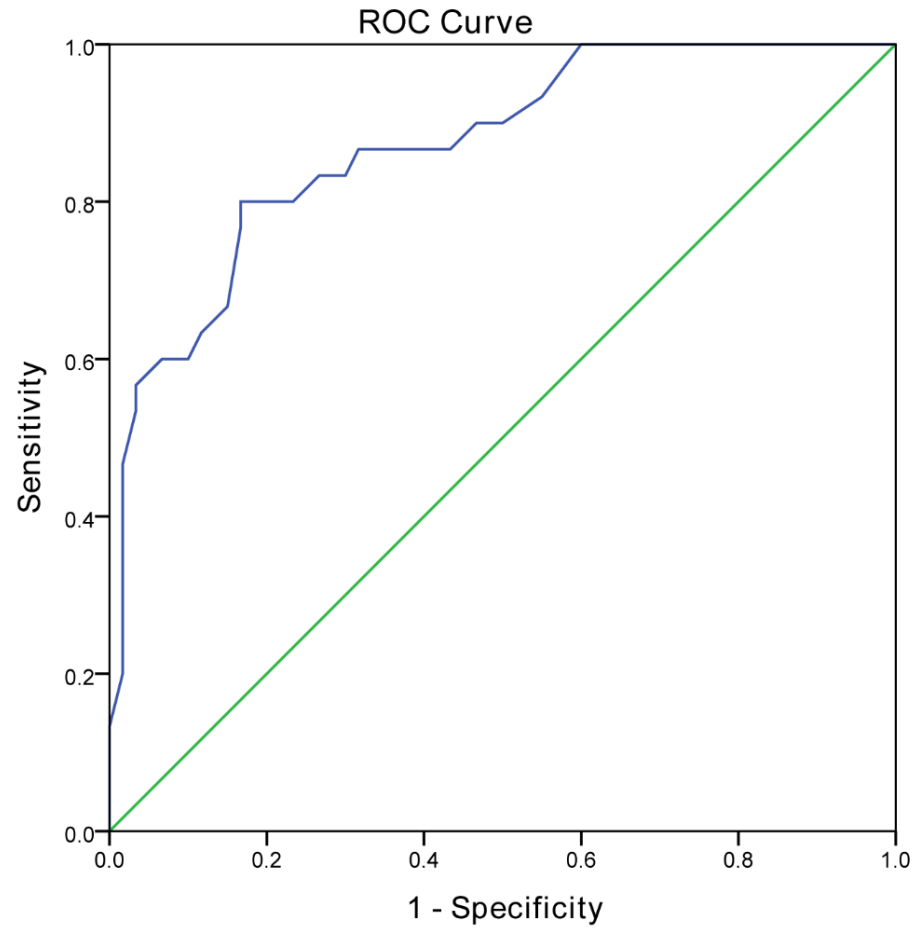

Figure 2. Receiver operating characteristic curve for the DCDQ-ES (cut-off score of 57) ( $n=90)$. 
Table 5 displays the research consequences of using the original Canadian cut-off points for identifying Spanish children with probable DCD, which were developed using logistic regression modelling [23]. As observed, $3.5 \%$ of children in the reference sample were diagnosed differently, depending on the cut-off point used. For the youngest children there is a $100 \%$ rate of agreement between both cut-off proposals, but in older groups this mismatch would result in a high rate of false-positive diagnoses. This mismatch is especially relevant in children aged 10 to 11 years, as $6.7 \%$ of Spanish children would get a false positive of probable DCD in research practice.

Table 5. Prevalence of children diagnosed with probable DCD using Canadian or Spanish cut-off points $(n=540)$.

\begin{tabular}{ccc}
\hline & \multicolumn{2}{c}{ Canadian Cut-Offs } \\
Spanish Cut-Offs & Probable not DCD & Probable DCD \\
Total sample & & $3.5 \%$ \\
Probably not DCD & $90.9 \%$ & $5.6 \%$ \\
Probable DCD & $0.0 \%$ & \\
6-7 years old & & $0.0 \%$ \\
Probably not DCD & $95.0 \%$ & $5.0 \%$ \\
Probable DCD & $0.0 \%$ & $3.9 \%$ \\
8-9 years old & & $5.6 \%$ \\
Probably not DCD & $90.5 \%$ & \\
Probable DCD & $0.0 \%$ & $6.7 \%$ \\
10-12 years old & & $5.1 \%$ \\
Probably not DCD & $87.2 \%$ &
\end{tabular}

DCD = Developmental Coordination Disorder.

\section{Discussion}

The aim of this research was to further validate the Spanish version of the DCDQ and to develop cut-off points for Spanish children using a randomly selected, sex and age-balanced sample of 540 Spanish typically developing children.

As motor coordination performance is a complex construct, different theories have been suggested and tested for its categorization when using and interpreting the DCDQ [23,43,44]. In this study, CFA analysis confirmed the original proposed three-factor structure, which is in line with the findings from Rivard et al. [44] and the validation study of the Italian version of the DCDQ [35]. Overall, these findings add to the evidence that motor coordination is a complex and multifactorial construct and that fine motor skills, coordination during movement and general coordination are interrelated factors but with unique differential aspects. For instance, girls and boys tend to show different motor coordination patterns in fine and gross motor skills, even when children come from different countries and cultural environments [21,45], and children with DCD struggle with different areas of motor coordination $[3,13]$. Therefore, it is necessary to assess each factor when exploring for DCD or coordination difficulties in daily living. Based upon the presented results, the authors recommend taking into account the specific problems in each of the three subscales in addition to interpreting the total score when using the DCDQ in a clinical context.

The DCDQ-ES has been previously cross-culturally adapted to the Spanish population, demonstrating that it is culturally and conceptually equivalent to the original DCDQ, and the preliminary validation study showed that the DCDQ-ES is a reliable tool for assessing motor performance in typically developing Spanish children [34]. In line with previous studies, findings from this further validation work report higher internal consistency values for the DCDQ-ES total scale and for the three subscales [24-31]. Cronbach's alpha values in other validation studies in European, Asian and Latin American populations range from 0.89 to 0.96 [24-31], demonstrating that the DCDQ is a reliable tool for assessing motor coordination and probable DCD. 
The DCDQ-ES showed a high capacity to discriminate between children with and without probable DCD. The pDCD group scored significantly lower on all of DCDQ-ES items, the total scale and each of the three subscales $(p<0.05)$. The total score of the DCDQ-ES significantly discriminated children in the pDCD group across the three age groups as well. The co-occurrence rate of other neurodevelopmental conditions within the $\mathrm{pDCD}$ group is in line with the high prevalence rates reported by previous research, particularly regarding ADHD and ASD [3,14,46-48]. Children with ADHD frequently present with motor coordination difficulties and DCD [3,49], and it has been questioned whether ADHD and DCD may pose as a unique disorder, but research demonstrates that they show differential motor, executive functioning and sensory processing characteristics and disparities in brain underpinnings, adding to the evidence of both disorders being commonly overlapping but different conditions [7,50,51].

Co-occurrence between DCD and ASD has been less explored, partially because assessment of motor coordination difficulties in children with ASD is reasonably more complex. However, the DSM-5 states that co-occurrence between both disorders is possible and research suggests that it may be quite frequent [2,3,52-54]. A recent study using a large sample of children with ASD $(n>11,000)$ estimates that prevalence of risk of DCD in this population is as high as 86.9\% [55]. Even if ASD commonly overlaps with DCD, research supports that both are different disorders with unique physiological and functional characteristics and intervention requirements [56]. For instance, Caeyenberghs et al. [57] found that children with DCD only and ASD only showed disorder-specific neural alterations, while children with both DCD and ASD exhibited distinct topological patterns, concluding that co-occurring children have a unique neural signature.

In this study, most of the items significantly discriminated children with pDCD only, pDCD/ADHD and $\mathrm{pDCD} / \mathrm{ASD}$, although some items (i.e., item 4,5 or 15) did not discriminate typically developing children from pDCD only children, which can be partially explained by the small sample size in this subgroup. However, the total and subscale scores of the DCDQ-ES significantly discriminated children with $\mathrm{pDCD}$ only, $\mathrm{pDCD} / \mathrm{ADHD}$ and $\mathrm{pDCD} / \mathrm{ASD}$, thus supporting the discriminant validity of the DCDQ-ES.

As expected, significant differences between age groups were found in both the DCDQ-ES total scale and all subscales. Older children scored significantly higher than younger children, which adds to the evidence that children improve their motor skills as they grow, as has been theorized previously by several authors, thus supporting the use of age-specific cut-off points [21,23,35,44,46].

Findings regarding sex differences in motor performance vary highly across cultural contexts and measures of assessment $[20,33,45]$. In this study, boys and girls showed a similar score on the DCDQ-ES total scale but had significant differences in the fine motor/handwriting subscale.

Outcomes regarding differences in motor coordination between boys and girls are inconclusive and vary according to country and measure of assessment [58-60]. For instance, Rivard et al. [44] reported that Canadian typically developing and DCD girls scored better on the DCDQ total scale than typically developing and DCD boys, respectively, while Caravale et al. [35] found that Italian boys and girls showed similar scores on the Italian DCDQ. Using the DCDDaily-Q, Delgado-Lobete et al. [45] found that both Spanish and Dutch girls showed better performance in fine motor activities than Spanish and Dutch boys, but differences in total performance varied according to sex and country.

These outcomes are in line with the findings from this study, and suggest that motor performance is probably influenced by cultural factors and daily activity participation. On the other side, typically developing boys are usually more proficient in gross motor skills than typically developing girls, while girls usually outperform boys in fine motor skills, but there is generally a higher proportion of males than females reported with DCD $[21,33,45,59,60]$. Thereby, it is possible that impairments in gross motor skills may be more evident than difficulties in fine motor performance, which could lead to girls with coordination motor struggles to go unnoticed.

As age was significantly associated with DCDQ-ES subscales and total scores, different cut-off points were calculated following the original age categorization of the DCDQ [23]. The resulting Spanish cut-offs reflected the lower mean scores found in typically developing Spanish children in 
comparison with the Canadian children, except for younger children. Identifying DCD in young children may be more complicated than in older children because motor performance is more variant and coordination difficulties can be overturned [3,33].

Country-adjusted cut-off points have also been developed for other Southern American and European versions of the DCDQ, and these are usually lower than the original ones $[35,61]$. The established cut-off points for Brazilian children are significantly lower than both the Canadian and the Spanish norms, indicating lower overall scores in the DCDQ for Brazilian children [61]. While Italian adjusted cut-off points are almost similar to the Spanish norms in younger children, they differ significantly in the 8-9 and 10-12-years-old groups [35], which in the Spanish situation may reflect an increasing improvement in motor performance with age [21]. This situation may be due to different motor coordination standards between North America and South America or Southern Europe, which are consistent with the different prevalence rates of probable DCD among these populations $[21,60]$. Interestingly, differences between Italian and Spanish cut-off points further support that variances in motor coordination performance exist even between regions that may be perceived as similar.

The 5 th percentile is often taken as the cut-off point in tools designed to identify the risk of DCD in research $[32,35,62-64]$, and so it is the cut-off point recommended by the authors when using the DCDQ in Spain to operationalize criterion B of the diagnostic criteria for DCD diagnosis in research practice. Conversely, the use of the 15th percentile is recommended in clinical practice. However, as the aim of the DCDQ-ES is to identify as many children with probable DCD as possible, different percentile scores are given so that researchers and healthcare practitioners can compare a child's performance in each of the three factors and the total scale in relation to the normative sample, thereby detecting those children with mild motor coordination difficulties in order to prompt strategies to prevent further consequences. An additional recommendation for clinicians would be to not only be alert to the total DCDQ-ES score but to notice whether the child scores lower than their peers in a particular area (i.e., control during movement, fine motor/handwriting or general coordination), as children with DCD present with a variety of motor coordination issues.

As expected, the Spanish recommended cut-off score for clinical practice in the overall sample, regardless of age group, is higher than the Canadian value (57 vs. 53). It is interesting to note that although this overall cut-off resulted in quite similar sensitivity values (Spanish $=77 \%$; Canadian $=$ $81 \%$ ), the specificity in the Spanish version is significantly higher (Spanish $=83 \%$; Canadian $=65 \%$ ).

However, sensitivity and specificity values for the clinical proposed Spanish cut-off were similar with that of the original DCDQ and other cross-cultural adaptations [23,25-27,30,35]. For instance, sensitivity and specificity of the German version of the DCDQ for a clinic sample was $72.7 \%$ and $95 \%$, while these values decreased to $30 \%$ and $86.7 \%$ in a community sample [25]. The Italian-adjusted cut-off scores resulted in a sensitivity of $59 \%$ and a specificity of $65 \%$ for a community-based sample [35], but these values increased to $88 \%$ and $96 \%$ if using a clinical DCD sample [27]. The sensitivity and specificity for Brazilian children is $73 \%$ and $86.6 \%$, respectively [26], and the European French values are similar as well (sensitivity $=85 \%$, specificity $=81.6 \%$ ) [30].

One important finding in this study was that using the non-country-adjusted cut-off points for Spanish children resulted in a significant mismatch and a high rate of false-positive diagnoses of probable DCD, especially in children older than 7 years. As previously discussed, the discrepancy between Canadian and Spanish norms could be explained by differences in motor coordination standards between regions, which have been reported in previous studies across European and American populations $[35,45,60,62]$. It may be possible that parents from different cultural and geographical backgrounds have distinct standards on rating their child's motor performance in comparison to other children.

These findings show that it is crucial to develop and promote the use of country-adjusted norms in order to prevent misleading outcomes in clinical and research practice. Possible clinical consequences of mistakenly identifying children with probable DCD include not only economic and resource costs but also the cost of putting families and children through unnecessary stress and potentially delaying a 
definite diagnosis. As the DCDQ-ES aims to operationalize criterion B of the DSM- 5 diagnostic criteria for DCD, a diagnosis of definite DCD only should be made after a comprehensive multidisciplinary evaluation $[3,33]$. An occupational therapy evaluation of the impact of motor deficits on a child's activities in daily living has specific relevance in the diagnosis of DCD (criterion B). Therefore, it is recommended to include pediatric occupational therapists in the multidisciplinary team.

Some limitations of this study should be addressed. One important limitation was that a definite diagnosis of DCD could not be established in the pDCD group. However, only children who scored at the most restrictive cut-off in the DCDDaily-Q were included in the $\mathrm{PDCD}$ group. Another limitation regarding the $\mathrm{pDCD}$ group is that most severe cases (i.e., children who had been referred for motor coordination difficulties in addition to another potential neurodevelopmental condition) were more likely to be recruited in this study, which may constitute a bias. A second limitation is that the sample size of the 10-11-years-old group in the $\mathrm{pDCD}$ group was very small. Additionally, our sample did not include children aged 12-15, therefore the norms for the older age group should be considered when assessing Spanish children older than 11 years. Finally, intra-rater reliability, test-retest reliability and concurrent validity with objective motor test batteries were not tested. Future research directions might include gathering data from children with a definite diagnosis of DCD in order to further test the sensibility and specificity of the proposed cut-off scores.

\section{Conclusions}

The present study has both research and clinical implications as it reports further information about the psychometric properties of the European Spanish version of the DCDQ and provides the reference norms for Spanish children. Findings show that the DCDQ-ES is a reliable and valid instrument for assessing motor coordination issues and for identifying children with probable DCD in Spanish context. Age-specific cut-off points adjusted to the Spanish population are provided for research and clinical purposes. The DCDQ-ES is a cost-effective, accessible and reliable measure for easy and quick assessment of motor coordination that may prompt further and comprehensive evaluation of potential DCD if needed. Health practitioners working in pediatric primary care or with children, such as occupational and physical therapists, can benefit from these findings and use the DCDQ-ES to operationalize criterion B of the diagnostic criteria for DCD.

Supplementary Materials: The following are available online at http://www.mdpi.com/1660-4601/17/7/2425/s1, Table S1: European Spanish version of the DCDQ.

Author Contributions: Conceptualization, R.M.-M., L.D.-L. and T.P.; methodology, R.M.-M., L.D.-L. and T.P.; validation, R.M.-M., L.D.-L., J.P., S.S.-d.-R. and T.P.; formal analysis, R.M.-M. and L.D.-L.; resources, R.M.-M., L.D.-L. and T.P.; data curation, R.M.-M. and L.D.-L.; writing-original draft preparation, R.M.-M. and L.D.-L.; writing-review and editing, R.M.-M., L.D.-L., J.P., S.S.-d.-R. and T.P.; visualization, R.M.-M., L.D.-L., J.P., S.S.-d.-R. and T.P.; supervision, J.P., S.S.-d.-R. and T.P.; project administration, R.M.-M., L.D.-L. and T.P.; funding acquisition, R.M.-M., L.D.-L., J.P. and T.P. All authors have read and agreed to the published version of the manuscript. R.M.-M. and L.D.-L. contributed equally.

Funding: This research was partially funded by the European Social Fund 2014-2020 and Galician Government, grant number ED481A-2018/150. The APC was funded by CITIC, Research Centre of the Galician University System, supported by the Consellería de Educación, Universidade e Formación Profesional of Xunta de Galicia through the European Regional Development Fund (ERDF) with 80\%, Operational Programme ERDF Galicia 2014-2020 and the remaining 20\% by the Secretaría Xeral de Universidades, grant number ED431G 2019/01.

Acknowledgments: The authors want to acknowledge the collaboration and participation of the schools and families involved in the data collection. The authors thank the original author of the DCDQ, Brenda Wilson, for giving us the permission to cross-cultural adapt and validate the DCDQ into European Spanish.

Conflicts of Interest: The authors declare no conflict of interest. The funders had no role in the design of the study; in the collection, analyses, or interpretation of data; in the writing of the manuscript, or in the decision to publish the results. 


\section{Appendix A}

Table A1. Age and sex for all groups $(n=570)$.

\begin{tabular}{ccc}
\hline Participants & N & Boys (N (\%)) \\
\hline Normative group & 540 & $270(50.0 \%)$ \\
6-7 years old & 180 & $90(50.0 \%)$ \\
8-9 years old & 180 & $90(50.0 \%)$ \\
10-12 years old & 180 & $90(50.0 \%)$ \\
pDCD group & 30 & $20(66.7)$ \\
6-7 years old & 11 & $8(72.7)$ \\
8-9 years old & 16 & $10(62.5)$ \\
10-11 years old & 3 & $1(33.3)$ \\
Control group & 60 & $40(66.7)$ \\
6-7 years old & 32 & $16(72.7)$ \\
8-9 years old & 32 & $20(62.5)$ \\
10-11 years old & 6 & $2(33.3)$ \\
\hline
\end{tabular}

\section{References}

1. Zwicker, J.G.; Missiuna, C.; Harris, S.R.; Boyd, L.A. Developmental coordination disorder: A review and update. Eur. J. Paediatr. Neurol. 2012, 16, 573-581. [CrossRef] [PubMed]

2. American Psychiatry Association. Diagnostic and Statistical Manual of Mental Disorders, 5th ed.; American Psychiatry Association: Washington, DC, USA, 2013.

3. Blank, R.; Barnett, A.L.; Cairney, J.; Green, D.; Kirby, A.; Polatajko, H.; Rosenblum, S.; Smits-Engelsman, B.; Sugden, D.; Wilson, P.; et al. International clinical practice recommendations on the definition, diagnosis, assessment, intervention, and psychosocial aspects of developmental coordination disorder. Dev. Med. Child Neurol. 2019, 61, 242-285. [CrossRef] [PubMed]

4. Cairney, J.; Hay, J.; Veldhuizen, S.; Missiuna, C.; Mahlberg, N.; Faught, B.E. Trajectories of relative weight and waist circumference among children with and without developmental coordination disorder. CMAJ 2010, 182, 1167-1172. [CrossRef] [PubMed]

5. Rivilis, I.; Hay, J.; Cairney, J.; Klentrou, P.; Liu, J.; Faught, B.E. Physical activity and fitness in children with developmental coordination disorder: A systematic review. Res. Dev. Disabil. 2011, 32, 894-910. [CrossRef] [PubMed]

6. Li, Y.C.; Wu, S.K.; Cairney, J.; Hsieh, C.Y. Motor coordination and health-related physical fitness of children with developmental coordination disorder: A three-year follow-up study. Res. Dev. Disabil. 2011, 32, 2993-3002. [CrossRef] [PubMed]

7. Delgado-Lobete, L.; Pértega-Díaz, S.; Santos-del-Riego, S.; Montes-Montes, R. Sensory Processing Patterns in Developmental Coordination Disorder, Attention Deficit Hyperactivity Disorder and Typical Development. Res. Dev. Disabil. 2020, 100, 103608. [CrossRef] [PubMed]

8. Harrowell, I.; Hollén, L.; Lingam, R.; Emond, A. Mental health outcomes of developmental coordination disorder in late adolescence. Dev. Med. Child Neurol. 2017, 59, 973-979. [CrossRef]

9. Lingam, R.; Jongmans, M.J.; Ellis, M.; Hunt, L.P.; Golding, J.; Emond, A. Mental health difficulties in children with developmental coordination disorder. Pediatrics 2012, 129, e882-e891. [CrossRef]

10. Cairney, J.; Rigoli, D.; Piek, J. Developmental coordination disorder and internalizing problems in children: The environmental stress hypothesis elaborated. Dev. Rev. 2013, 33, 224-238. [CrossRef]

11. Crane, L.; Sumner, E.; Hill, E.L. Emotional and behavioural problems in children with Developmental Coordination Disorder: Exploring parent and teacher reports. Res. Dev. Disabil. 2017, 70, 67-74. [CrossRef]

12. Magalhães, L.C.; Cardoso, A.A.; Missiuna, C. Activities and participation in children with developmental coordination disorder: A systematic review. Res. Dev. Disabil. 2011, 32, 1309-1316. [CrossRef] [PubMed]

13. Van der Linde, B.W.; van Netten, J.J.; Otten, E.; Postema, K.; Geuze, R.H.; Schoemaker, M.M. Activities of Daily Living in Children With Developmental Coordination Disorder: Performance, Learning, and Participation. Phys. Ther. 2015, 95, 1496-1506. [CrossRef] [PubMed] 
14. Kaiser, M.L.; Schoemaker, M.M.; Albaret, J.M.; Geuze, R.H. What is the evidence of impaired motor skills and motor control among children with attention deficit hyperactivity disorder (ADHD)? Systematic review of the literature. Res. Dev. Disabil. 2015, 36, 338-357. [CrossRef] [PubMed]

15. Rosenblum, S.; Waissman, P.; Diamond, G.W. Identifying play characteristics of pre-school children with developmental coordination disorder via parental questionnaires. Hum. Mov. Sci. 2017, 53, 5-15. [CrossRef] [PubMed]

16. Summers, J.; Larkin, D.; Dewey, D. Activities of daily living in children with developmental coordination disorder: Dressing, personal hygiene, and eating skills. Hum. Mov. Sci. 2008, 27, 215-229. [CrossRef]

17. Summers, J.; Larkin, D.; Dewey, D. What Impact does Developmental Coordination Disorder have on Daily Routines? Int. J. Disabil. Dev. Educ. 2008, 55, 131-141. [CrossRef]

18. Harrowell, I.; Hollén, L.; Lingam, R.; Emond, A. The impact of developmental coordination disorder on educational achievement in secondary school. Res. Dev. Disabil. 2018, 72, 13-22. [CrossRef]

19. Missiuna, C.; Rivard, L.; Bartlett, D. Early identification and risk management of children with Developmental Coordination Disorder. Pediatr. Phys. Ther. 2003, 15, 32-38. [CrossRef]

20. Schoemaker, M.M.; Flapper, B.; Verheij, N.P.; Wilson, B.N.; Reinders-Messelink, H.A.; de Kloet, A. Evaluation of the Developmental Coordination Disorder Questionnaire as a screening instrument. Dev. Med. Child Neurol. 2006, 48, 668-673. [CrossRef]

21. Delgado-Lobete, L.; Santos-del-Riego, S.; Pértega-Díaz, S.; Montes-Montes, R. Prevalence of suspected developmental coordination disorder and associated factors in Spanish classrooms. Res. Dev. Disabil. 2019, 86, 31-40. [CrossRef]

22. Carballal Mariño, M.; Gago Ageitos, A.; Ares Álvarez, J.; Del Río Garma, M.; García Cendón, C.; Goicoechea Castaño, A.; Pena Nieto, J. Prevalencia de trastornos del neurodesarrollo, comportamiento y aprendizaje en Atención Primaria. An. Pediatr. 2018, 89, 153-161. [CrossRef] [PubMed]

23. Wilson, B.N.; Crawford, S.G.; Green, D.; Roberts, G.; Aylott, A.; Kaplan, B.J. Psychometric properties of the revised Developmental Coordination Disorder. Phys. Occup. Ther. Pediatr. 2009, 29, 182-202. [CrossRef] [PubMed]

24. Martini, R.; St-Pierre, M.F.; Wilson, B.N. French Canadian cross-cultural adaptation of the Developmental Coordination Disorder Questionnaire ‘07: DCDQ-FC. Can. J. Occup. Ther. 2011, 78, 318-327. [CrossRef] [PubMed]

25. Kennedy-Behr, A.; Wilson, B.N.; Rodger, S.; Mickan, S. Cross-cultural adaptation of the developmental coordination disorder questionnaire 2007 for German-speaking countries: DCDQ-G. Neuropediatrics 2013, 44, 245-251. [PubMed]

26. Prado, M.S.; Magalhães, L.C.; Wilson, B.N. Cross-cultural adaptation of the developmental coordination disorder questionnaire for Brazilian children. Braz. J. Phys. Ther. 2009, 13, 236-243. [CrossRef]

27. Caravale, B.; Baldi, S.; Gasparini, C.; Wilson, B.N. Cross-cultural adaptation, reliability and predictive validity of the Italian version of Developmental Coordination Disorder Questionnaire (DCDQ). Eur. J. Paediatr. Neurol. 2014, 18, 267-272. [CrossRef]

28. Nowak, A. Cross-cultural adaptation of the Developmental Coordination Disorder Questionnaire (DCDQ'07) for the population of Polish children. Biomed. Hum. Kinet. 2016, 8, 17-23. [CrossRef]

29. Patel, P.; Gabbard, C. Adaptation and Preliminary Testing of the Developmental Coordination Disorder Questionnaire (DCDQ) for Children in India. Phys. Occup. Ther. Pediatr. 2017, 37, 170-182. [CrossRef]

30. Ray-Kaeser, S.; Thommen, E.; Martini, R.; Jover, M.; Gurtner, B.; Bertrand, A.M. Psychometric assessment of the French European Developmental Coordination Disorder Questionnaire (DCDQ-FE). PLoS ONE 2019, 24, e0217280. [CrossRef]

31. Salamanca-Duque, L.M.; Naranjo Aristizábal, M.M.C.; González Marín, A.P. Validity and reliability of developmental coordination disorder questionnaire Spanish version. Rev. Cienc. Salud 2013, 11, $263-274$.

32. Van der Linde, B.W.; van Netten, J.J.; Otten, B.E.; Postema, K.; Geuze, R.H.; Schoemaker, M.M. Psychometric properties of the DCDDaily-Q: A new parental questionnaire on children's performance in activities of daily living. Res. Dev. Disabil. 2014, 35, 1711-1719. [CrossRef] [PubMed]

33. Montes-Montes, R.; Delgado-Lobete, L.; Pereira, J.; Schoemaker, M.M.; Santos-del-Riego, S.; Pousada, T. Identifying Children with Developmental Coordination Disorder via Parental Questionnaires. Spanish Reference Norms for the DCDDaily-Q-ES and Correlation with the DCDQ-ES. Int. J. Environ. Res. Public Health 2020, 17, 555. [CrossRef] [PubMed] 
34. Montes-Montes, R.; Delgado-Lobete, L.; Pereira, J.; Pousada, T. Cross-Cultural Adaptation and Preliminary Validation of the Developmental Coordination Disorder Questionnaire for European Spanish Children. Am. J. Occup. Ther. 2020, in press.

35. Caravale, B.; Baldi, S.; Capone, L.; Presaghi, F.; Balottin, U.; Zoppello, M. Psychometric properties of the Italian versión of the Developmental Coordination Disorder Questionnaire (DCDQ-Italian). Res. Dev. Disabil. 2015, 36, 543-550. [CrossRef] [PubMed]

36. Hennessy, S.; Bilker, W.B.; Berlin, J.A.; Strom, B.L. Factors influencing the optimal control-to-case ratio in matched case-control studies. Am. J. Epidemiol. 1999, 149, 195-197. [CrossRef] [PubMed]

37. Pértega Díaz, S.; Pita Fernández, S. Cálculo del tamaño muestral en estudios de casos y controles. Cad Aten Primaria 2002, 9, 148-150.

38. Forero, C.G.; Maydeu-Olivares, A.; Gallardo-Pujol, D. Factor analysis with ordinal indicators: A monte carlo study comparing DWLS and ULS estimation. Struct. Equ. Model. 2009, 16, 625-641. [CrossRef]

39. Yang-Wallentin, F.; Jöreskog, K.G.; Luo, H. Confirmatory factor analysis of ordinal variables with misspecified models. Struct. Equ. Model. 2010, 17, 392-423. [CrossRef]

40. West, S.G.; Finch, J.F.; Curran, P.J. Structural equation models with non-normal variables. In Structural Equation Modeling: Concepts, Issues and Applications; Hoyle, R.H., Ed.; Sage: Thousand Oaks, CA, USA, 1995; pp. 56-75.

41. Hu, L.; Bentler, P.M. Cutoff criteria for fit indexes in covariance structure analysis: Conventional criteria versus new alternatives. Struct. Equ. Model. 1999, 6, 1-55. [CrossRef]

42. Kline, R.B. Principles and Practice of Structural Equation Modeling, 2nd ed.; Guilford Press: New York, NY, USA, 2005.

43. Nakai, A.; Miyachi, T.; Okada, R.; Tani, I.; Nakajima, S.; Onishi, M.; Fujita, C.; Tsujii, M. Evaluation of the Japanese version of the Developmental Coordination Disorder Questionnaire as a screening tool for clumsiness of Japanese children. Res. Dev. Disabil. 2011, 32, 1615-1622. [CrossRef]

44. Rivard, L.; Missiuna, C.; McCauley, D.; Cairney, J. Descriptive and factor analysis of the Developmental Coordination Disorder Questionnaire (DCDQ’07) in a population-based sample of children with and without Developmental Coordination Disorder. Child Care Health Dev. 2014, 40, 42-49. [CrossRef] [PubMed]

45. Delgado-Lobete, L.; Montes-Montes, R.; Pértega-Díaz, S.; Santos-del-Riego, S.; Cruz-Valiño, J.M.; Schoemaker, M.M. Interrelation of Individual, Country and Activity Constraints in Motor Activities of Daily Living among Typically Developing Children: A Cross-sectional Comparison of Spanish and Dutch Populations. Int. J. Environ. Res. Public Health 2020, 17, 1705. [CrossRef] [PubMed]

46. Kaplan, B.J.; Dewey, D.M.; Crawford, S.G.; Wilson, B.N. The term comorbidity is of questionable value in reference to developmental disorders: Data and theory. J. Learn. Disabil. 2001, 34, 555-565. [CrossRef] [PubMed]

47. Miyahara, M.; Möbs, I.; Doll-Tepper, G. Severity of hyperactivity and the comorbidity of hyperactivity with clumsiness in three sample sources: School, support group and hospital. Child Care Health Dev. 2001, 27, 413-424. [CrossRef] [PubMed]

48. Green, D.; Baird, G.; Sugden, D.A. A pilot study of psychopathology in developmental coordination disorder. Child Care Health Dev. 2006, 32, 741-750. [CrossRef] [PubMed]

49. Romero-Ayuso, D.; Maciver, D.; Richmond, J.; Jorquera-Cabrera, S.; Garra-Palud, L.; Zabala-Baños, C.; Toledano-González, A.; Triviño-Juárez, J.-M. Tactile Discrimination, Praxis and Cognitive Impulsivity in ADHD Children: A Cross-Sectional Study. Int. J. Environ. Res. Public Health 2020, 17, 1897. [CrossRef] [PubMed]

50. Goulardins, J.B.; Rigoli, D.; Licari, M.; Piek, J.P.; Hasue, R.H.; Oosterlaan, J.; Oliveira, J.A. Attention deficit hyperactivity disorder and developmental coordination disorder: Two separate disorders or do they share a common etiology. Behav. Brain Res. 2015, 292, 484-492. [CrossRef]

51. McLeod, K.R.; Langevin, L.M.; Dewey, D.; Goodyear, B.G. Atypical wihin- and between-hemisphere motor network functional connections in children with developmental coordination disorder and attention-deficit/hyperactivity disorder. Neuroimage Clin. 2016, 12, 157-164. [CrossRef]

52. Holloway, J.M.; Long, T.M.; Biasini, F. Relationships between Gross Motor Skills and Social Function in Young Boys with Autism Spectrum Disorder. Pediatr. Phys. Ther. 2018, 30, 184.

53. Hilton, C.L.; Zhang, Y.; Whilte, M.R.; Klohr, C.L.; Constantino, J.N. Motor Impairment in Sibling Pairs Concordant and Discordant for Autism Spectrum Disorders. Autism 2012, 16, 430-441. [CrossRef] 
54. Bhat, A.N.; Landa, R.J.; Galloway, J.C. (Cole) Current Perspectives on Motor Functioning in Infants, Children, and Adults with Autism Spectrum Disorders. Phys. Ther. 2011, 91, 1116-1129. [CrossRef] [PubMed]

55. Bhat, A.N. Is Motor Impairment in Autism Spectrum Disorder (ASD) Distinct From Developmental Coordination Disorder (DCD)? A Report from the SPARK Study. Phys. Ther. 2020, pzz190. [CrossRef] [PubMed]

56. Kilroy, E.; Cermak, S.A.; Aziz-Zadeh, L. A Review of Functional and Structural Neurobiology of the Action Observation Network in Autism Spectrum Disorder and Developmental Coordination Disorder. Brain Sci. 2019, 9, 75. [CrossRef] [PubMed]

57. Caeyenberghs, K.; Taymans, T.; Wilson, P.H.; Vanderstraeten, G.; Hosseini, H.; van Waelvelde, H. Neural signatura of developmental coordination disorder in the structural connectome independent of comorbid autism. Dev. Sci. 2016, 19, 599-612. [CrossRef]

58. Faebo Larsen, R.; Hvas Mortensen, L.; Martinussen, T.; Nybo Andersen, A.M. Determinants of developmental coordination disorder in 7-year-old children: A study of children in the Danish National Birth Cohort. Dev. Med. Child Neurol. 2013, 55, 1016-1022. [CrossRef]

59. Psotta, R.; Hendl, J.; Frömel, K.; Lehnert, M. The second version of the Movement Assessment Battery for children: A comparative study in 7-10 year old children from the Czech Republic and the United Kingdom. Acta Gymn. 2012, 42, 19-27. [CrossRef]

60. Valentini, N.C.; Oliveira, M.A.; Pangelinan, M.M.; Whitall, J.; Clark, J.E. Can the MABC discriminate and predict motor impairment? A comparison of Brazilian and American children. IJTR Int. J. Ther. Rehabil. 2017, 24, 105-113. [CrossRef]

61. Ferreira, L.; Gabbard, C.; Lopes Vieira, J.L.; Norraila da Silva, P.; Cheuczuk, F.; Ferreira da Rocha, F.; Matias de Souza, V.F.; Caçola, F. Reconsidering the use of cut-off scores: DCDQ-Brazil. Rev. Bras. Med. Esporte 2019, 25, 344-348. [CrossRef]

62. Niemeijer, A.S.; van Waelvelde, H.; Smits-Engelsman, B.C. Crossing the North Sea seems to make DCD disappear: Cross-validation of Movement Assessment Battery for Children-2 norms. Hum. Mov. Sci. 2015, 39, 177-188. [CrossRef]

63. Geuze, R.H.; Jongmans, M.J.; Schoemaker, M.M.; Smits-Engelsman, B.C. Clinical and research diagnostic criteria for developmental coordination disorder: A review and discussion. Hum. Mov. Sci. 2001, 20, 7-47. [CrossRef]

64. Smits-Engelsman, B.; Schoemaker, M.; Delabastita, T.; Hoskens, J.; Geuze, R. Diagnostic criteria for DCD: Past and future. Hum. Mov. Sci. 2015, 42, 293-306. [CrossRef] [PubMed] 